\title{
Nitrogen Removal from the Saline Sludge Liquor by Electrochemical Denitrification
}

\author{
Z.M. Xie*, X.Y. Li* ${ }^{*}$ and K.Y. Chan** \\ *Department of Civil Engineering, The University of Hong Kong, Pokfulam Road, \\ Hong Kong, China ( ${ }^{\#} E-m a i l: x$ xlia@hkucc.hku.hk) \\ **Department of Chemistry, The University of Hong Kong, Pokfulam Road, Hong \\ Kong, China
}

\begin{abstract}
Sludge liquor from the sludge dewatering process has a high ammonia content. In the present study, a lab-scale electrochemical (EC) system with a pair of Ti electrode plates was used for treating the sludge centrate liquor of digested sludge with a $\mathrm{NH}_{4}{ }^{+}-\mathrm{N}$ of around $500 \mathrm{mg} / \mathrm{L}$. The sludge liquor had a high salinity due to seawater being used for toilet flushing in Hong Kong. The results show that the EC process is highly effective for denitrification of the saline sludge liquor. Complete nitrogen removal could be achieved within $1 \mathrm{hr}$ or so. The rate of EC denitrification increased with the current intensity applied. The best current efficiency for nitrogen removal was obtained for a gap distance between the electrodes at $8 \mathrm{~mm}$. Electrochlorination was considered to be the major mechanism of EC denitrification. The formation of chlorination by-products (CBPs) appeared to be minimal with the total trihalomethanes (THM) detected at a level of $300 \mu \mathrm{g} / \mathrm{L}$ or lower. The power consumption for EC denitrification of the sludge liquor was around $23 \mathrm{kWh} / \mathrm{kg} \mathrm{N}$. Additional electro-flocculation with a pair of iron needle electrodes could enhance the flocculation and subsequent sedimentation of colloidal organics in the sludge liquor, increasing the organic removal from less than $30 \%$ to more than $70 \%$. Therefore, the EC process including both electro-denitrification and electro-flocculation can be developed as the most cost-effective method for treatment of the saline sludge liquor.
\end{abstract}

Keywords: Denitrification, electrochemical, sludge liquor treatment, wastewater treatment.

\section{Introduction}

Secondary biological wastewater treatment produces a large volume of sludge wastes. The sludge collected from primary and secondary clarifiers is usually processed with anaerobic digestion followed by dewatering prior to its final disposal. The sludge liquor out of the dewatering unit is then returned to the inlet of the treatment system. Although the flow rate of the sludge liquor is low, accounting for about $1 \%$ of the influent, it contains a high nitrogen content with a $\mathrm{NH}_{4}{ }^{+}-\mathrm{N}$ between 500 to $800 \mathrm{mg} / \mathrm{L}$. The ammonia loading from sludge liquor contributes to $10-20 \%$ of the influent nitrogen loading. Removing this ammonia loading will either improve the performance or increase the capacity of the mainstream wastewater treatment process for nutrient removal (Jetten et al., 1997). In addition, separate treatment of the sludge liquor can take advantage of the high $\mathrm{NH}_{4}{ }^{+}$concentration in the liquor, which 
eventually increases the overall cost-effectiveness of a municipal wastewater treatment plant (Arnold et al., 2000; Kolisch and Rolfs, 2000).

Electrochemical (EC) method can be considered for treatment of the sludge liquor. An EC system is simple and robust in structure and operation. During EC treatment the sludge liquor will be forced through a reactor of electrolysis, in which electro-chlorination and the subsequent ammonia oxidisation are expected. Due to the shortage of freshwater supply in recent years, seawater has been increasingly used for domestic purposes, such as toilet flushing, in Hong Kong and a few coastal cities in China. The inclusion of seawater in sewage increases its salinity content, which can largely improve the performance of the EC process (Li et al., 2002; Diao et al., 2004). Moreover, the effluent quality of EC denitrification is expected to be more reliable due to its simple working conditions compared to other nitrogen removal processes. In the present study, laboratory experiments were carried out to investigate the effectiveness of EC treatment of saline sludge liquor for denitrification and organic removal. The influences of system and operational parameters, such as the current intensity, gap distance between the electrodes, power input and contact time, on the performance of EC treatment were also evaluated.

\section{Methods}

\section{Characteristics of the sludge centrate samples}

Sludge liquor was collected from a local municipal sewage treatment works, Shatin Sewage Treatment Works (STW) in Hong Kong, in which the conventional activated sludge process is used. Sludges from both primary and secondary sedimentation tanks are mixed and treated with anaerobic digestion of around 10 days. The digested sludge is then dewatered by centrifugation to a solid content of around $30 \%$, while the sludge centrate is returned to the main stream of sewage flow for treatment. The raw sludge centrate collected from the dewatering unit was dark-yellow in colour with a $\mathrm{NH}_{4}{ }^{+}-\mathrm{N}$ content of around $500 \mathrm{mg} / \mathrm{L}$ (Table 1). Due to the usage of seawater for toilet flushing in Hong Kong, seawater accounts for around $20 \%$ of the sewage influent to the Shatin STW. As a result, the sludge liquor samples had a high salinity with a $\mathrm{Cl}^{-}$concentration of more than $5000 \mathrm{mg} / \mathrm{L}$.

Table 1. Sludge centrate.

\begin{tabular}{l|l}
\hline Parameter & Value \\
\hline $\mathrm{NH}_{4}{ }^{+}-\mathrm{N}(\mathrm{mg} / \mathrm{L})$ & $518 \pm 137$ \\
$\mathrm{BOD}(\mathrm{mg} / \mathrm{L})$ & $160 \pm 40$ \\
$\mathrm{COD}(\mathrm{mg} / \mathrm{L})$ & $224 \pm 84$ \\
$\mathrm{TOC}(\mathrm{mg} / \mathrm{L})$ & $62 \pm 11$ \\
$\mathrm{Cl}^{-}(\mathrm{mg} / \mathrm{L})$ & $5278 \pm 422$ \\
$\mathrm{pH}$ & $7.70 \pm 0.21$ \\
\hline
\end{tabular}

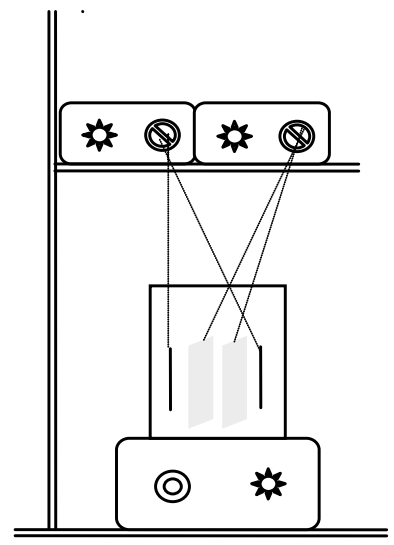

Figure 1. Experimental set-up (EC denitrification + EC flocculation).

\section{Electrochemical treatment system}

The EC experiment system included an EC reactor on a magnetic stirrer, two potentiostats as the DC power suppliers, a pair of titanium electrode plates for electro-denitrification, and sometimes a pair of needle iron electrodes for additional electro-flocculation (Figure 1). The 
EC reactor was a 1-L beaker filled with the raw sludge liquor. The electrode plates were made of Ti mesh rectangular in shape with a dimension of $5 \times 4 \mathrm{~cm}^{2}$. The electrode surface was coated with $\mathrm{RuO}_{2}, \mathrm{TiO}_{2}$ and $\mathrm{ZrO}_{2}$ by thermal deposition to improve its corrosion resistance. The gap distance between the two electrode plates could be varied for different testing conditions. The two power sources, when both were used, could charge the pair of Ti plates and the pair of Fe needles separately. The DC input from any of the power suppliers was adjustable by varying both the current, I, and the voltage, V. Because of different treatment purposes served, the power input to the Ti plates for denitrification was much greater than that to the Fe needle electrodes for dissolving iron and electro-flocculation.

\section{Electro-denitrification and electro-flocculation experiments}

The EC treatment experiments were carried out in batch mode. The electrodes were immersed into the sludge liquor in the EC reactor. Three gap distances between the Ti plates, 3, 8 and $15 \mathrm{~mm}$, were tested. For each electrode setting, electrolysis experiments were conducted at different current input, including 0.5, 1.0, 1.5, 2.0 and $2.5 \mathrm{~A}$, resulting in different current intensities for EC denitrification. For each test run which lasted from $1 \mathrm{hr}$ to more than 2 hrs depending on the current intensity, samples were withdrawn from the reactor at various time intervals for evaluation of the treatment result, particularly on the removal of total inorganic nitrogen (TIN). The current efficiency of electrolysis for denitrification can be estimated (Prentice, 1991) by

$$
\eta=\frac{3 F \Delta N}{14 I t}
$$

where: $\Delta N$ is the amount of TIN removed from $1 \mathrm{~L}$ of the sludge liquor within a treatment time of $t$ at the current $I$, and $F$ is the Faraday constant (96,500 coulombs).

In combination with EC denitrification, electro-flocculation was tested for additional organic removal. The pair of iron needles placed $65 \mathrm{~mm}$ apart were charged at a low current. With the DC charged, iron dissolved into the solution at a controlled rate by adjusting the current input. $\mathrm{Fe}^{2+}$ was expected to function as a flocculant for particulate organics in the sludge liquor. By the end of EC treatment, the sludge solution was flocculated for $30 \mathrm{~min}$ followed by sedimentation of $120 \mathrm{~min}$. In addition to the nitrogen content, the supernatant was analysed for organic and SS reductions, and the sludge accumulated in sediment was measured.

\section{Analytical methods}

The input of DC current and voltage could be read directly from the power suppliers. All analyses of conventional water quality parameters, such as the biological oxygen demand (BOD), chemical oxygen demand (COD) and the suspended solids (SS), were performed following the Standard Method (1998). Free chlorine and chloride $\left(\mathrm{Cl}^{-}\right)$in a solution were measured with a portable datalogging spectrophotometer (DR/2010, HACH) following the methods defined by the manufacturer. The $\mathrm{NH}_{3}-\mathrm{N}$ concentration was measured by the electrochemical method using an ammonia electrode and a potentiometer (920A, ORION). Chloramines of $\mathrm{NH}_{2} \mathrm{Cl}, \mathrm{NHCl}_{2}$ and $\mathrm{NCl}_{3}$ were determined for their concentrations by the titration method in accordance with the Standard Methods (1998). An UV-visible spectrometer (Lambda 12, Perkin Elmer, 1cm path length) was used for $\mathrm{NO}_{3}{ }^{-}$and $\mathrm{NO}_{2}{ }^{-}$ measurements following the Standard Methods (1998). The total organic carbon (TOC) was determined by a TOC analyser (TOC-5000A, Shimadzu) based on the combustion-infrared method. The solution $\mathrm{pH}$ and turbidity were measured by a $\mathrm{pH}$ meter (420A, ORION) and a turbidimeter (2100N, HACH), respectively. A jar-test device (PB700, Phipps \& Bird) with a flat paddle mixer $\left(3.8 \times 1.25 \mathrm{~cm}^{2}\right)$ was employed for the flocculation and experiment test. 
Formation of trihalomathanes (THM) after the EC treatment in a sample was also assessed following the extraction with pentane. The extracted sample was then analyzed for the THM concentration by a gas chromatograph (GC6890, Hewlett Packard) equipped with a capillary column (30.0 m $\times 320 \mu \mathrm{m} \times 1.0 \mathrm{~mm}$ nominal, DB-5, Agilent J\&W), an autosampler and a linearised electron capture detector (ECD) ( $\mathrm{Li}$ and Chu, 2003).

\section{Results and Discussion}

\section{Electrochemical denitrification of the sludge centrate liquor}

The electrochemical treatment was demonstrated to be highly effective for denitrification of the saline sludge liquor. Nitrogen measured as TIN was removed continuously from the sludge centrate samples by electrolysis. With a sufficient duration of the EC treatment, complete denitrification could be achieved (Figure 2). An increase in the current intensity resulted in a faster rate of TIN reduction. For example, at a current intensity of $50 \mathrm{~mA} / \mathrm{cm}^{2}$ for sludge liquor with a $\mathrm{NH}_{4}{ }^{+}-\mathrm{N}$ of more than $350 \mathrm{mg} / \mathrm{L}$, denitrification could be completed within $150 \mathrm{~min}$. This treatment time was shortened to around $60 \mathrm{~min}$ at an elevated current intensity of $125 \mathrm{~mA} / \mathrm{cm}^{2}$. Thus, higher current input favoured the kinetics of EC denitrification.

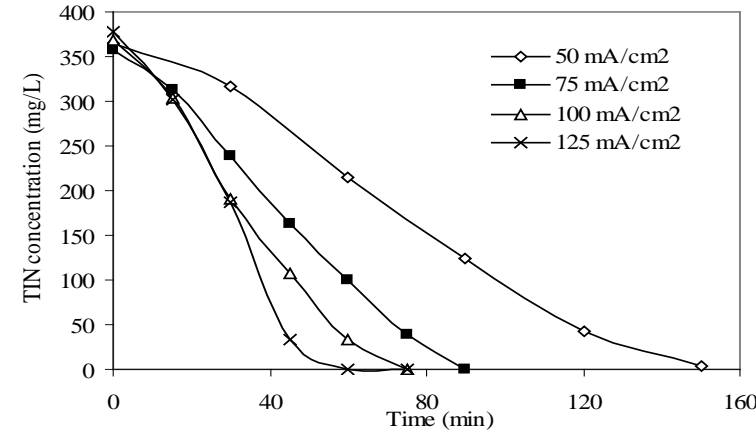

Figure 2. TIN removal as a function of the contact time and current intensity with a gap distance of $8 \mathrm{~mm}$ between the electrodes.

As anticipated, electrolysis of the ammonia solution formed intermediate products of chloramines prior to the completion of denitrification. However, there did not appear to be significant accumulation of chloramines, including $\mathrm{NH}_{2} \mathrm{Cl}, \mathrm{NHCl}_{2}$ and $\mathrm{NCl}_{3}$, during the $\mathrm{EC}$ treatment (Figure 3a). $\mathrm{NH}_{2} \mathrm{Cl}-\mathrm{N}$ could reach a concentration of around $20 \mathrm{mg} / \mathrm{L}$, which disappeared from the solution by the end of EC denitrification. Formation of $\mathrm{NO}_{3}{ }^{-}$and $\mathrm{NO}_{2}{ }^{-}$ were hardly detectable during the EC process. Thus, $\mathrm{NH}_{4}{ }^{+}$was the predominant TIN species throughout the EC treatment.

Chloride in the sludge liquor was electrolysed to chlorine, which was believed to be essential to EC denitrification. While both free chlorine and combined chlorine were present in the solution, free chlorine accounted for the major fraction of total chlorine in the reactor (Figure 3b). The combined chlorine of $\mathrm{NH}_{2} \mathrm{Cl}$ and $\mathrm{NHCl}_{2}$ was found in a low and rather stable concentration level. Upon complete $\mathrm{NH}_{4}{ }^{+}-\mathrm{N}$ removal, the combined chlorine was gradually eliminated, while free chlorine was found to increase with time by continuous electrolysis.

The importance of chloride to EC denitrification was also demonstrated with a model water of $\left(\mathrm{NH}_{4}\right)_{2} \mathrm{SO}_{4}$ solution. Without salt $\left(\mathrm{Cl}^{-}\right)$addition, electrolysis of the model solution did not result in any effective nitrogen removal. While $\mathrm{Cl}^{-}$was dosed into the solution at a level of $4000 \mathrm{mg} / \mathrm{L}$, the same denitrification result that was obtained for the actual sludge centrate was reproduced. Thus, electro-chlorination can be considered as the major mechanism responsible for EC denitrification of the saline sludge liquor (Stoner and Cahen, 1982; Casson and Bess, 2003). 
One of the major concerns in use of EC treatment methods is the formation of chlorination
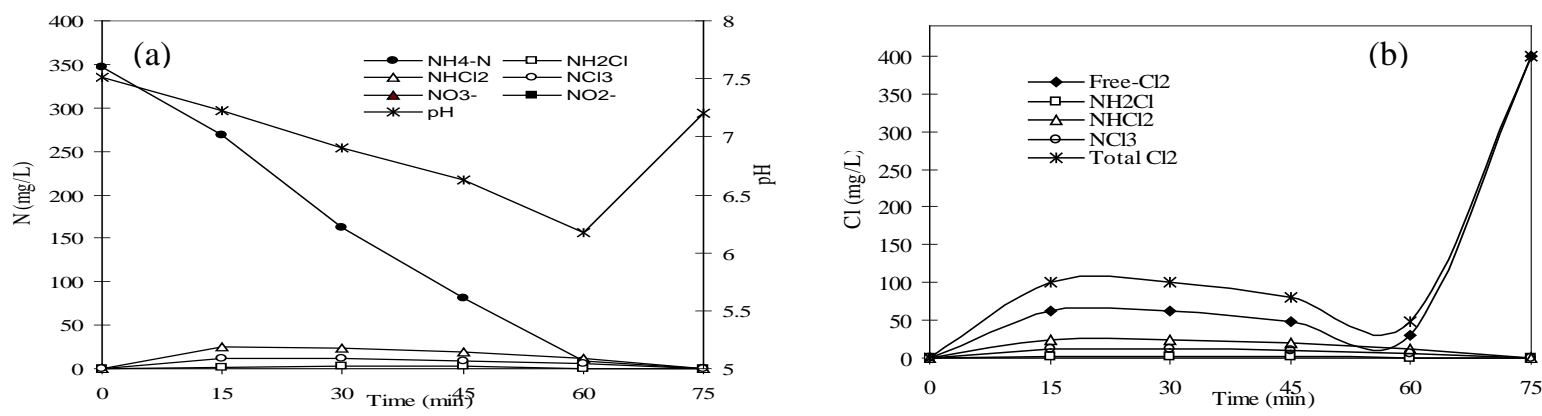

Figure 3. (a) Nitrogen removal as a function of treatment time and (b) chlorine compounds during the EC process at a current intensity of $125 \mathrm{~mA} / \mathrm{cm}^{2}$ with an electrode gap of $3 \mathrm{~mm}$.

by-products (CBPs). As an indicator, trihalomethanes (THMs) were used for assessing the potential CBP problem in EC denitrification of the sludge liquor. The total THM in the treated sludge liquor was found to range only from 200 to $300 \mu \mathrm{g} / \mathrm{L}$. The low THM formation during the electro-chlorination was likely due to the short contact time of $1 \mathrm{hr}$ or so used. Since the sludge liquor will be returned to the main stream of sewage flow, the low level of THMs in the denitrified liquor will be degraded by the downstream biological treatment. Hence, it is predictable that the accumulation of THMs and other CBPs during EC denitrification will be insignificant, which is not supposed to cause any deterioration in the effluent quality of wastewater treatment.

\section{Electro-chlorination for denitrification of the sludge liquor}

Electro-chlorination is believed to be essential to EC denitrification of the saline sludge liquor. In the presence of $\mathrm{Cl}^{-}, \mathrm{NH}_{4}{ }^{+}$and other impurities, electro-chlorination for nitrogen removal is a complex process. The reaction of $\mathrm{Cl}^{-}$electrolysis can be written (Parsons, 1959; Casson and Bess, 2003) as

$$
\mathrm{Cl}^{-}+2 \mathrm{H}_{2} \mathrm{O} \rightarrow \mathrm{HOCl}+\mathrm{OH}^{-}+\mathrm{H}_{2} \uparrow
$$

The principle chlorination reaction in the presence of $\mathrm{NH}_{4}{ }^{+}$(Metcalf \& Eddy, 2003) is

$$
2 \mathrm{NH}_{4}{ }^{+}+3 \mathrm{HOCl} \rightarrow \mathrm{N}_{2} \uparrow+3 \mathrm{H}_{2} \mathrm{O}+2 \mathrm{H}^{+}+3 \mathrm{Cl}^{-}
$$

Combining equations (2) and (3) produces the overall reaction of EC denitrification:

$$
2 \mathrm{NH}_{4}{ }^{+} \stackrel{\text { Power }}{\longrightarrow} \mathrm{N}_{2} \uparrow+3 \mathrm{H}_{2} \uparrow+2 \mathrm{H}^{+}
$$

Electrolysis of $\mathrm{NH}_{4}{ }^{+}$would lead to an accumulation of $\mathrm{H}^{+}$ions and thus a $\mathrm{pH}$ decrease, which was observed during the EC treatment tests (Figure 3a). After the completion of nitrogen removal, reaction (3) became dominant. Thus, a turn point of the $\mathrm{pH}$ value was expected, after which the $\mathrm{pH}$ would increase with time. This $\mathrm{pH}$ change during the EC process was well demonstrated by the test results (Figure 3a).

\section{Operational conditions on EC denitrification}

For a given EC system, parameters such as the current intensity, the gap distance between the electrodes and treatment time regulate the effectiveness and performance of EC denitrification. As shown in Figure 2, an increase in the current input would accelerate the nitrogen removal process by electrolysis. However, for the same gap distance between the electrodes, a higher current intensity might not improve the efficiency of the current used for denitrification. Instead, a too high current input would decrease the current efficiency (Figure 4). In the EC treatment, in addition to $\mathrm{NH}_{4}^{+}$electrolysis to nitrogen gas, current input was also consumed for electrolysis reactions of $\mathrm{H}_{2} \mathrm{O}, \mathrm{Cl}^{-}$and other compounds, as well as for heat 
generation. It is apparent that the fraction of current used for denitrification did not increase with the current intensity, although a higher current favoured the nitrogen removal kinetics.

The gap distance of the electrodes had more profound effect on the current efficiency for EC denitrification. Among the 3 distances examined, a gap of $8 \mathrm{~mm}$ gave the best current efficiency as high as $65 \%$ or more. Increasing the gap to $15 \mathrm{~mm}$ resulted in a large reduction of the current efficiency to around 55\%. More electricity was likely wasted for heat generation as the gap distance increased, as evidenced by the temperature rise observed. However, when the gap was reduced to only $3 \mathrm{~mm}$, the current efficiency dropped more dramatically to around $40 \%$. Bubbles trapped between the narrow gap could have a negative effect on the EC nitrogen removal process. Possible short circuit between the electrodes would considerably lower the current efficiency for $\mathrm{NH}_{4}{ }^{+}$ electrolysis. Thus, an appropriate gap distance between the electrodes should be adopted in the EC system to ensure a high

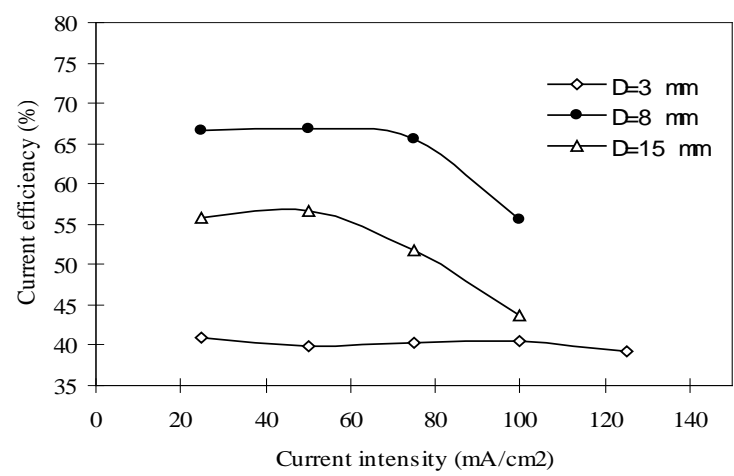

Figure 4. Current efficiency as a function of current input for different electrode gaps in EC denitrification. current efficiency for denitrification.

For a batch operation of $\mathrm{NH}_{4}{ }^{+}$electrolysis, the amount of nitrogen removal from the sludge liquor depended directly on the power input into the EC treatment system. It was estimated that the power consumption rate for nitrogen removal from the sludge liquor was about 23 $\mathrm{kWh} / \mathrm{kg} \mathrm{N}$ under the optimum operation conditions. This cost is comparable with other denitrification processes (Teichgraeber and Stein, 1994). In addition, EC denitrification is simple in structure and easy in operation. It has the potential to be developed as a robust and cost-effectiveness technology for separate treatment of saline sludge liquor.

\section{Electro-flocculation for organic reduction}

The EC process did not appear to be highly effective for the removal of organic materials from the sludge liquor, although a certain extent of reduction in the organic content was observed (Figure 5). Some organic molecules could likely be oxidised by EC reactions or the oxidising products of the EC process. However, EC oxidisation was not expected to be highly efficient for large organic molecules and particulate organics. With the electro-flocculation examined in this study, organic removal of the sludge liquor was improved considerably (Table 2, Figure 5).

\begin{tabular}{lllllll}
\hline $\begin{array}{l}\text { Electro- } \\
\text { flocculation }\end{array}$ & $\begin{array}{l}\mathrm{NH}_{4}{ }^{+}-\mathrm{N} \\
(\mathrm{mg} / \mathrm{L})\end{array}$ & $\begin{array}{l}\mathrm{TOC} \\
(\mathrm{mg} / \mathrm{L})\end{array}$ & $\begin{array}{l}\mathrm{COD} \\
(\mathrm{mg} / \mathrm{L})\end{array}$ & $\begin{array}{l}\mathrm{SS} \\
(\mathrm{mg} / \mathrm{L})\end{array}$ & $\begin{array}{l}\text { Sludge } \\
(\mathrm{mg} / \mathrm{L})\end{array}$ & $\begin{array}{l}\text { Turbidity } \\
(\mathrm{NTU})\end{array}$ \\
\hline No & 0.18 & 44.4 & 100 & 6.74 & 0.22 & 17.8 \\
Yes & 0.12 & 17.2 & 44 & 2.89 & 441 & 0.57 \\
\hline
\end{tabular}

Table 2. Effect of electro-flocculation on the results of EC sludge liquor treatment. 
Electrolysis with the iron electrodes would dissolve $\mathrm{Fe}^{2+}$ into the sludge solution. $\mathrm{Fe}^{2+}$ and its hydrolysis products are excellent flocculants. They are capable to destabilise the colloidal solution of large organic molecules, particulate organics and other impurities. In the present
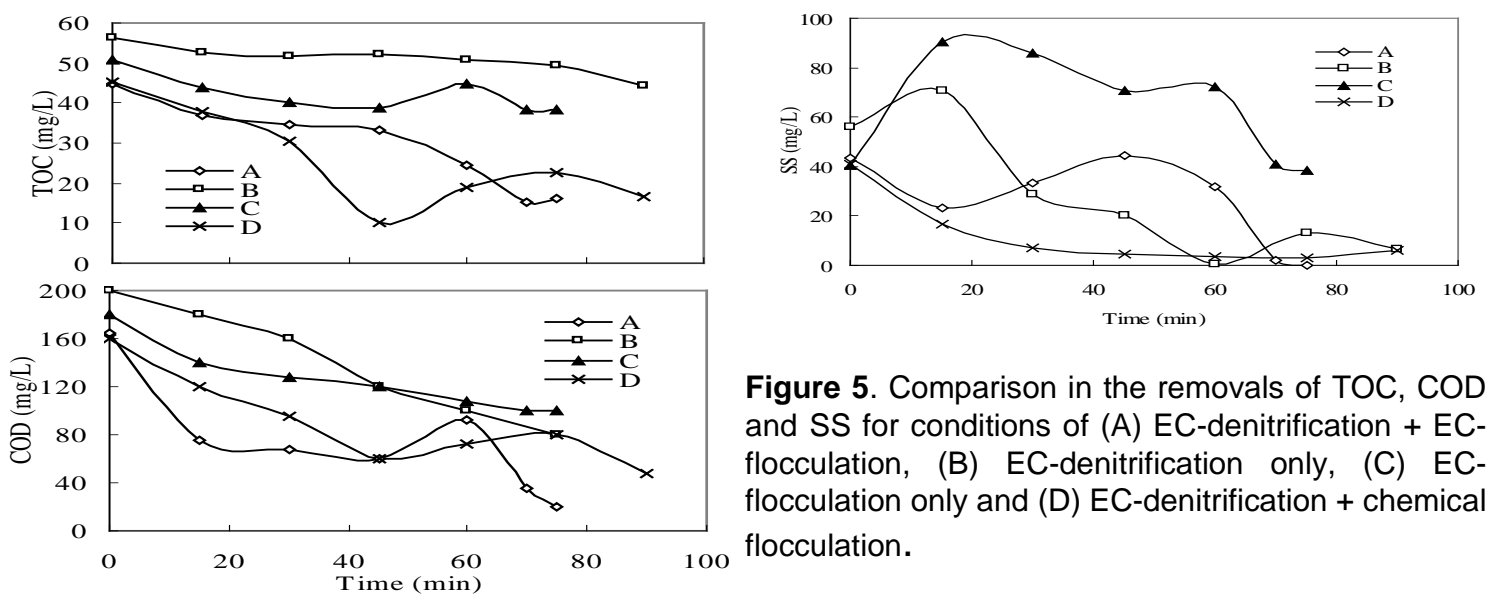

Figure 5. Comparison in the removals of TOC, COD and SS for conditions of (A) EC-denitrification + ECflocculation, (B) EC-denitrification only, (C) ECflocculation only and (D) EC-denitrification + chemical flocculation.

tests, $\mathrm{Fe}^{2+}$ compounds produced by the EC process functioned as a flocculant to promote flocculation of organic materials. Large flocs formed by electro-flocculation were effectively removed in the subsequent sedimentation. With the EC system, the rate of $\mathrm{Fe}^{2+}$ dissolving into the sludge liquor from the iron anode could be well controlled by regulating the current input. Electro-flocculation did not have any adversary effect on EC denitrification. Instead, the combined action of electro-denitrification with electro-flocculation had better treatment results in organic and SS removals (Figure 5). The electrolysed effluent after flocculation and sedimentation was transparent and colourless with a rather low turbidity (Table 2). It should be noted, however, over-dosage of $\mathrm{Fe}^{2+}$ by the EC reaction did not result in more organic and SS reductions from the sludge liquor, while sludge production was largely increased.

In comparison, electro-flocculation without EC denitrification only removed a part of organic and SS and had no function of nitrogen removal. Chemical flocculation using $\mathrm{FeCl}_{3}$ in combination with EC denitrification had a similar treatment result as the coupled process of EC denitrification and electro-flocculation. However, chemical flocculation lowered the solution $\mathrm{pH}$ to around 3 and produced more sludge sediment. In actual application, chemical flocculation would require more facilities and operation attention. Therefore, electrodenitrification together with electro-flocculation appears to be the best treatment approach for nitrogen removal and organic reduction of sludge liquor.

\section{Conclusions}

A lab-scale electrochemical (EC) system with a pair of Ti electrode plates was used for treatment of a saline sludge centrate liquor. The experimental results show that the EC process is highly effective for denitrification of the saline sludge liquor with a $\mathrm{NH}_{4}{ }^{+}-\mathrm{N}$ of around $500 \mathrm{mg} / \mathrm{L}$. Complete nitrogen removal could be achieved within a treatment time of 1 hr or so. The best current efficiency for nitrogen removal was obtained with a gap distance between the electrodes at $8 \mathrm{~mm}$, followed by the gap of $15 \mathrm{~mm}$. However, as the gap distance was narrowed to only $3 \mathrm{~mm}$, the worst current efficiency was observed. Electro-chlorination was considered to be the major mechanism for EC denitrification. Nonetheless, there was not significant accumulation of chloramines during the EC reactions. The formation of chlorination by-products (CBPs) appeared to be minimal as the total trihalomethanes (THM) was only $300 \mu \mathrm{g} / \mathrm{L}$ or below. The power consumption rate for nitrogen removal of the sludge liquor was around $23 \mathrm{kWh} / \mathrm{kg} \mathrm{N}$. Additional electro-flocculation with a pair of iron needle 
electrodes could enhance the flocculation and subsequent sedimentation of colloidal organics in the sludge liquor, which increased the organic removal from less than $30 \%$ to more than $70 \%$. Therefore, the EC process including both electro-denitrification and electro-flocculation could be developed as the most cost-effective method for the separate treatment of the saline sludge liquor.

\section{Acknowledgements}

This research was supported by Grant HKU7008/01E from the Research Grants Council (RGC) of the Hong Kong SAR Government and funding from the University Research Committee (URC) of the University of Hong Kong. The technical assistance of Mr. K.C.H. Wong is highly appreciated.

\section{References}

Arnold E., Boehm B. and Wilderer P.A. (2000). Application of activated sludge and biofilm sequencing batch reactor technology to treat reject water from sludge dewatering systems: a comparison. Water Science and Technology , 41(1), 115-122.

Casson L.W. and Bess J.W. Jr. (2003). Conversion to On-site Sodium Hypochlorite Generation: Water and Wastewater Applications, CRC Press, New York, USA, pp. 2122.

Diao H.F., Li X.Y., Gu J.D., Shi H.C. and Xie Z.M. (2004) Electron microscopic investigation of the bactericidal action of electrochemical disinfection in comparison with chlorination, ozonation and Fenton reaction. Process Biochemistry, 39, 1421-1426.

Jetten M.S.M., Horn S.J. and van Loosdrecht M.C.M. (1997). Towards a more sustainable municipal wastewater treatment system. Water Science and Technology, 35(9), 171-180.

Kolisch G. and Rolfs T. (2000) Integrated sidestream treatment for enhanced enlargement of sewage plants. Water Science and Technology, 41(9), 155-162.

Li X.Y. and Chu H.P. (2003). Membrane bioreactor for the drinking water treatment of polluted surface water supplies. Water Research, 37, 4781-4791.

Li X.Y., Ding F., Lo P.S.Y. and Sin S.H.P. (2002). Electrochemical disinfection of saline wastewater effluent. J Environmental Engineering, ASCE, 128, 697-704.

Metcalf \& Eddy (2003). Wastewater Engineering Treatment and Reuse, $4^{\text {th }}$ edn, McGrawHill, New York, USA, pp. 1238-1239.

Parsons R. (1959). Handbook of Electrochemical Constants, Butterworth's Scientific, London, UK, pp. 69-73.

Prentice G. (1991). Electrochemical Engineering Principles, Prentice-Hall, Upper Saddle River, NJ, USA, pp. 12-13.

Standard Methods for the Examination of Water and Wastewater (1998). 20 ${ }^{\text {th }}$ edn, American Public Health Association/American Water Works Association/Water Pollution Control Federation, Washington DC, USA.

Stoner G.E. and Cahen G.L. (1982). The mechanism of low frequency AC electrochemical disinfection. Bioelectrochemistry and Bioengineering, 9, 229-243.

Teichgraeber B. and Stein A. (1994) Nitrogen elimination from sludge treatment reject water - comparison of the steam-stripping and denitrification processes. Water Science and Technology, 30(6), 41-51. 